\title{
Hybrid BFPSO Approach for Effective Tuning of PID Controller for Load Frequency Control Application in an Interconnected Power System
}

\author{
S.Anbarasi ${ }^{\dagger}$ and S. Muralidharan*
}

\begin{abstract}
Penetration of renewable energy sources makes the modern interconnected power systems to have more intelligence and flexibility in the control. Hence, it is essential to maintain the system frequency and tie-line power exchange at nominal values using Load Frequency Control (LFC) for efficient, economic and reliable operation of power systems. In this paper, intelligent tuning of the Proportional Integral Derivative (PID) controller for LFC in an interconnected power system is considered as a main objective. The chosen problem is formulated as an optimization problem and the optimal gain parameters of PID controllers are computed with three innovative swarm intelligent algorithms named Particle Swarm Optimization (PSO), Bacterial Foraging Optimization Algorithm (BFOA) and hybrid Bacterial Foraging Particle Swarm Optimization (BFPSO) and a comparative study is made between them. A new objective function designed with necessary time domain specifications using weighted sum approach is also offered in this report and compared with conventional objective functions. All the simulation results clearly reveal that, the hybrid BFPSO tuned PID controller with proposed objective function has better control performances over other optimization methodologies.
\end{abstract}

Keywords: Bacterial foraging optimization algorithm, Hybrid bacterial foraging particle swarm optimization algorithm, Load frequency control, Particle swarm optimization algorithm, PID controller

\section{Introduction}

Now a day in modern interconnected power systems, the non-renewable energy resources are increasingly superseded by renewable energy resources. The varying nature of renewable energy causes uncertainties in power systems [1]. Hence LFC is essential to maintain the system frequency and tie-line power exchange at nominal values for efficient, economic and reliable operation of interconnected power systems. In LFC the primary means of frequency control in a LFC loop are executed with the governor mechanism, and the supplementary control is offered with conventional controllers like Proportional (P), Integral (I), Proportional Integral (PI) and PID controller [2, 3]. Among these controllers, the PID controller is generally chosen because of its proper control performances, fast response and its robustness towards the non linearity, time varying dynamics, perturbations and other factors.

However, tuning the gain parameters of the PID controllers is always a challenging task. These gain parameters are generally computed through trial and error or conventional $\mathrm{ZN}$ methods $[4,5]$. The trial and error method is time consuming and it provides suboptimal results in most of the instances. The gain parameters calculated

$\dagger$ Corresponding Author: Research Scholar, Dept. of Electrical and Electronic Engineering, Mepco Schlenk Engineering College, Sivakasi. (tsoundarapandiananbu@gmail.com)

* Professor, Dept. of Electrical and Electronic Engineering, Mepco Schlenk Engineering College, Sivakasi. (yes_murali@yahoo.com) Received: February 28, 2016; Accepted: February 17, 2017 by $\mathrm{ZN}$ method is not pliable for the nonlinearities and disturbances introduced in the system, which may obligate the system towards instability. To overcome these drawbacks, abundant computational optimization techniques $[6-8$, and 9] have been developed in recent years for the optimal tuning of PID parameters in LFC. In this paper an attempt is made to develop three optimization methodologies such as PSO, BFOA and BFPSO for effective tuning of PID controller in LFC system and a comparative analysis is made between them.

The PSO algorithm is developed based on the social behaviors of birds flocking or fish schooling [10]. Nevertheless, this approach may suffer from the partial optimism, which induces the less exact at the ordinance of its fastness and the focal point, and results local optimal solutions. The BFOA mimics the group foraging strategy of Escherichia Coli (E.Coli) bacteria in multioptimal function optimization [11]. It has been demonstrated as a powerful evolutionary computational technique, compared to other intelligent approaches in many optimization problems $[12,13]$. However, the BFOA approach experienced many difficulties which will be briefly discussed in section 3.3 of this paper. To surmount these difficulties, the BFOA is commonly combined with some other PSO or Genetic algorithm [14, 15 and 16]. In view of the above, an attempt has been attained in this paper for the optimal design of BFPSO based PID controller for LFC in two area interconnected power system.

In addition, a new objective function is also proposed in 
this paper that includes the minimization of fundamental time domain specifications such as steady state error, maximum peak, settling time, rise time and peak time with suitable weighting factors. Hence, the aim of the present work is twofold: First one is to demonstrate the advantages of BFPSO over other optimization methodologies designed in this paper such as PSO, BFOA and also with recently documented results of Craziness Based Particle Swarm Optimization (CBPSO) [17] which are recently confronted in the literature for the similar problem; the second one is to show the advantages of using a proposed objective function over conventional objective functions like Integral Square Error (ISE) and Integral Time Square Error (ITSE). Accordingly, detailed analyses are made in this paper by examining the transient performances of the system, the convergence characteristics of the algorithms and also the robustness of the system. All these analyses undoubtedly reveal the superiority of the proposed BFPSO tuned PID controller over PSO, BFOA and CBPSO [17] and also confirm that the proposed objective function outperform established objective functions.

\section{Description of LFC in a Two Area Thermal Power System}

A widely used standard two area thermal test system with Governor Dead-Band (GDB) nonlinearity shown in Fig. 1 is considered in this research study. Normally, GDB is the hysteresis effect mainly arises due to the mechanical friction, backlash and valve overlaps in hydraulic relays. The GDB will make significant disturbances on the governor's performance and also on the transient performances like amplitude and settling time of the oscillations [17]. Hence, the effect of GDB nonlinearity is considered in this paper.

In this research work, enhancing the performance of LFC with PID controller is designed as an optimization problem and PSO, BFOA and BFPSO algorithms are suggested for effective tuning of PID controller parameters.

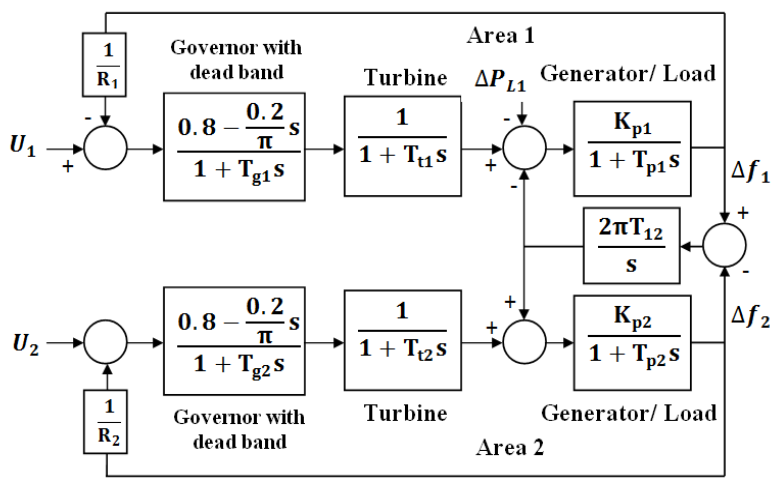

Fig. 1. Linearised model of two area Load Frequency Control (LFC) system
In order to converge to the optimal solution, three minimization objective functions are considered in the present paper (1). The first and second are commonly used conventional objective functions named ISE $\left(\mathrm{J}_{1}\right)$ and ITSE $\left(\mathrm{J}_{2}\right)$ respectively $(2,3)$. These two objective functions focus only on minimization of error in output frequency deviations in area-1 and $2\left(\Delta \mathrm{F}_{1}\right.$ and $\left.\Delta \mathrm{F}_{2}\right)$ and tie line power deviation $\left(\Delta \mathrm{P}_{\text {tie }}\right)$ of the LFC system. Hence, to enhance the control performance of the optimized PID controller, a third novel objective function $\left(\mathrm{J}_{3}\right)$ is proposed in this paper which includes, minimization of settling time, overshoots, rise time and peak time of $\Delta \mathrm{F}_{1}, \Delta \mathrm{F}_{2}$ and $\Delta \mathrm{P}_{\text {tie }}$ responses in addition to the error minimization (4).

$$
\begin{gathered}
\text { Fitness function }=\operatorname{Min}(\mathrm{J}) \\
J_{1}=\int_{0}^{\mathrm{t}_{\text {sim }}}\left(\Delta \mathrm{F}_{1}^{2}\right)+\left(\Delta \mathrm{F}_{2}^{2}\right)+\left(\Delta \mathrm{P}_{\mathrm{Tie}}^{2}\right) \cdot \mathrm{dt} \\
J_{2}=\int_{0}^{\mathrm{t}_{\text {sim }}}\left(\Delta \mathrm{F}_{1}^{2}\right)+\left(\Delta \mathrm{F}_{2}^{2}\right)+\left(\Delta \mathrm{P}_{\mathrm{Tie}}^{2}\right) \cdot \mathrm{t} . \mathrm{dt} \\
\mathrm{J}_{3}=\mathrm{w}_{1} \Delta \mathrm{e}_{\mathrm{T}}+\mathrm{w}_{2} \mathrm{P}_{\mathrm{m}}+\mathrm{w}_{3} \mathrm{~T}_{3}+\mathrm{w}_{4} \mathrm{~T}_{\mathrm{r}}+\mathrm{w}_{5} \mathrm{~T}_{\mathrm{p}} \\
\Delta \mathrm{e}_{\mathrm{T}}=\Delta \mathrm{F}_{1}+\Delta \mathrm{F}_{2}+\Delta \mathrm{P}_{\text {tie }}
\end{gathered}
$$

where, $\Delta \mathrm{F}_{1}$ is the frequency deviation in area $1, \Delta \mathrm{F}_{2}$ is the frequency deviation in area-2, $\Delta \mathrm{P}_{\text {tie }}$ is the frequency deviation in area- $1 \Delta \mathrm{e}_{\mathrm{T}}$ is the total output error (5), $\mathrm{t}_{\mathrm{sim}}$ is the simulation timings, and $\mathrm{w}_{1}, \mathrm{w}_{2}, \mathrm{w}_{3}, \mathrm{w}_{4}$ and $\mathrm{w}_{5}$ are the weighting factors and their values are problem dependant. In this paper, the values of weighting factors are chosen as $\mathrm{w}_{1}=10000, \mathrm{w}_{2}=10, \mathrm{w}_{3}=0.01, \mathrm{w}_{4}=10$ and $\mathrm{w}_{5}=0.1$. Likewise, $\mathrm{J}$ is the fitness value of particle, $\mathrm{P}_{\mathrm{m}}$ is the maximum peak of the output wave form and $T_{s}, T_{r}$ are the settling time and rise time respectively. The nominal system parameters of two area thermal power systems investigated in this paper are same as the parameter quoted in references $[17,18]$.

They are:

$$
\begin{aligned}
& \mathrm{P}_{\mathrm{r} 1}=\mathrm{P}_{\mathrm{r} 2}=1000 \mathrm{MW} ; \mathrm{f}=60 \mathrm{~Hz} ; \mathrm{T}_{\mathrm{g} 1}=\mathrm{T}_{\mathrm{g} 2}=0.2 \mathrm{~s} ; \\
& \mathrm{T}_{\mathrm{t} 1}=\mathrm{T}_{\mathrm{t} 2}=0.3 \mathrm{~s} ; \mathrm{T}_{\mathrm{p} 1}=\mathrm{T}_{\mathrm{p} 2}=20 \mathrm{~s} ; \mathrm{T}_{12}=0.0731 ; \\
& \mathrm{B}_{1}=\mathrm{B}_{2}=0.425 ; \mathrm{K}_{\mathrm{p} 1}=\mathrm{K}_{\mathrm{p} 2}=120 \mathrm{~Hz} / \mathrm{pu} \mathrm{MW} ; \\
& \mathrm{R}_{1}=\mathrm{R}_{2}=2.4 \mathrm{~Hz} / \mathrm{pu} \mathrm{MW} .
\end{aligned}
$$

\section{Optimization Algorithms for Tuning PID Controller}

\subsection{Particle swarm optimization algorithm}

PSO is a population based search algorithm where each individual is referred to as particle and represents a candidate solution. The essential PSO parameters are initialized in this paper are: dimension of problem $(\mathrm{p})=6$; size of $\operatorname{swarm}(\mathrm{n})=100$; number of iterations $(\mathrm{t})=80$; acceleration coefficients $\left(c_{1}, c_{2}\right)=0.12,1.2$; inertia weight $(\mathrm{w})=0.85 ; \mathrm{r}_{1}$ and $\mathrm{r}_{2}$ are two $\mathrm{n} \times \mathrm{n}$ diagonal matrices over an interval $(0,1)$. The procedural steps of PSO for the 
proposed LFC problem are stated as follows.

Initially, in a six dimensional search space, the control parameters in area-1 $\left(\mathrm{K}_{\mathrm{p} 1}, \mathrm{~K}_{\mathrm{i} 1}, \mathrm{~K}_{\mathrm{d} 1}\right)$ and area-2 $\left(\mathrm{K}_{\mathrm{p} 2}, \mathrm{~K}_{\mathrm{i} 2}\right.$, $\mathrm{K}_{\mathrm{d} 2}$ ), are generated randomly within a specified range (6) as set of positional values.

$$
\begin{gathered}
0 \leq \mathrm{K}_{\mathrm{pi}} \cdot \mathrm{K}_{\mathrm{i} 1} \cdot \mathrm{K}_{\mathrm{di}} \cdot \mathrm{K}_{\mathrm{i} 2} \cdot \mathrm{K}_{\mathrm{d} 2} \leq 1 \\
J(\mathrm{i})=\text { Function}(\mathrm{P}(:, \mathrm{i}))
\end{gathered}
$$

Let the index of $n$ be represented as $i$, the index of iteration be represented as $t$ and the positional values of particles are represented as P. The fitness of all positional values (7) in a swarm is computed from any one of the objective function $(2,3,4)$ described in section 2 . The least fitness value and equivalent positional values of each swarm is termed as $\mathrm{J}_{\text {local }}$ and $\mathrm{P}_{\text {local }}$ correspondingly. Further, the least fitness value among $\mathrm{J}_{\text {local }}$ is computed as $\mathrm{J}_{\text {global }}$ and corresponding positional value is termed as $\mathrm{P}_{\text {global }}$. Certain velocity, which progressively gets close to $\mathrm{P}_{\text {local }}$ and $\mathrm{P}_{\text {global }}$ is then calculated (8) and the current position can be modified (9) for the next iteration employing this velocity.

$$
\begin{gathered}
\mathrm{V}_{\mathrm{i}}^{\mathrm{t}+1}=\mathrm{WV}_{\mathrm{i}}^{t}+\mathrm{c}_{1} * \mathrm{r}_{1}\left(\mathrm{P}_{\text {local }}-\mathrm{P}_{\mathrm{i}}\right)+\mathrm{c}_{2} * \mathrm{r}_{2}\left(\mathrm{P}_{\text {local }}-\mathrm{P}_{\mathrm{i}}\right) \\
\mathrm{P}_{\mathrm{i}}^{\mathrm{t}+1}=\mathrm{P}_{\mathrm{i}}^{\mathrm{t}}+\mathrm{V}_{\mathrm{i}}^{\mathrm{t}+1}
\end{gathered}
$$

where, the second part in equation (8) which contains the variable $\mathrm{P}_{\text {local }}$ is known as cognitive component and the third part of same equation which contains the variable $\mathrm{P}_{\text {global }}$ is known as social component.

\subsection{Bacterial foraging optimization algorithm}

The BFOA, mimics the foraging strategy of E.Coli bacteria in a nutrient search space. It has been widely accepted as a global optimization algorithm of current interest for distributed optimization and control. Normally, the E.Coli bacteria undergo four stages during the foraging strategy. They are Chemotaxis, swarming, reproduction and elimination dispersal respectively [19].

\section{Initialization:}

In initialization, all the essential parameters of the BFOA algorithm are initialized. In this research work, the following BFOA parameters are initialized [12, 15].

Dimension of problem $(\mathrm{p})=6$; Number of bacteria $(\mathrm{S})=$ 20; Number of Chemotaxis $\left(\mathrm{N}_{\mathrm{c}}\right)=10$; Number of reproduction steps $\left(\mathrm{N}_{\mathrm{re}}\right)=4$; Probability of eliminationdispersal $\left(\mathrm{P}_{\mathrm{ed}}\right)=0.25$; Number of elimination-dispersal events $\left(\mathrm{N}_{\mathrm{ed}}\right)=2$; depth of attractant $\left(\mathrm{d}_{\mathrm{att}}\right)=$ height of repellent $\left(\mathrm{h}_{\text {rep }}\right)=0.01$; width of attractant $\left(\mathrm{w}_{\mathrm{att}}\right)=0.004$; width of repellent $\left(\mathrm{w}_{\text {rep }}\right)=10$.

\section{Chemotaxis:}

Let, the index of $\mathrm{S}$ be represented as $\mathrm{i}, \mathrm{N}_{\mathrm{c}}$ denoted as $\mathrm{j}$, $\mathrm{N}_{\mathrm{re}}$ indicated by $\mathrm{k}$ and $\mathrm{N}_{\mathrm{ed}}$ represented as $\mathrm{l}$ and the iterations are framed with these indexes. Initially, S number of random control parameters for area-1 and area-2 as a set of positional values $(\mathrm{P})$ within a specified range (6) for area-1 and area-2 are generated in a search space. For every iteration, the fitness value $(\mathrm{J})$ of each particle and their positional values $(\mathrm{P})$ are computed (10).

$$
J(\mathrm{i}, \mathrm{j}, \mathrm{k}, \mathrm{l})=\text { Function }(\mathrm{P}(\mathrm{i}, \mathrm{j}, \mathrm{k}, \mathrm{l}))
$$

The excellent solution is then located with the minimum fitness value employing one of the objective function $(2,3$, 4) described in section 2 . In computational programming it is just done by sorting all the fitness values in descending order and selecting the last one (11). Then, each particle makes a chemotactic movement in random direction as indicated in (12)

$$
\begin{gathered}
\mathrm{J}_{\text {last }}=\mathrm{J}(\mathrm{i}, \mathrm{j}, \mathrm{k}, \mathrm{l}) \\
\mathrm{P}(\mathrm{i}, \mathrm{j}+\mathrm{l}, \mathrm{k}, \mathrm{l})=\mathrm{P}(\mathrm{i}, \mathrm{j}, \mathrm{k}, \mathrm{l})+\mathrm{C}(\mathrm{i}) \phi(\mathrm{j})
\end{gathered}
$$

where, C(i) (for $\mathrm{i}=1,2, \ldots \mathrm{S}$ ) is the size of step taken in random direction $\varphi(j)$. The value of $\varphi(j)$ can be calculated with a random vector (13).

$$
\phi(\mathrm{j})=\frac{\Delta(\mathrm{i})}{\sqrt{\Delta^{\mathrm{T}(\mathrm{i})} \cdot \Delta(\mathrm{i})}}
$$

where, $\Delta$ indicates a vector in random direction whose elements are in the range of $[-1,1]$. After the chemotactic movement the particles reach a new position $P(i, j+1, k, 1)$ in search space. The fitness value for this new position can be evaluated (14) and the best fitness value is again computed and stored as $\mathrm{J}_{\text {last }}(11)$.

$$
J(\mathrm{i}, \mathrm{j}+1, \mathrm{k}, \mathrm{l})=\operatorname{Function}(\mathrm{P}(\mathrm{i}, \mathrm{j}+1, \mathrm{k}, \mathrm{l}))
$$

When, the fitness value $\mathrm{J}$ evaluated for the current chemotactic step $J(i, j+1, k, l)$ is less than the previous one $\mathrm{J}(\mathrm{i}, \mathrm{j}, \mathrm{k}, \mathrm{l})$, another step will be taken by every particle in the same direction. Otherwise, the bacterium will tumble in random direction. This consecutive movement lead the particles to move towards the direction of decreasing the fitness function and finally to reach the best fitness value.

\section{Swarming:}

Swarming is an interesting grouping behaviour that is often termed as cell to cell signalling of the motile species. In optimization problem this phenomenon is used to help the particles to move towards a global optimal solution. The mathematical representation of this swarming with the combined attractant and repellent parameters are shown in the equations below (15 and 16).

$$
\mathrm{J}_{\mathrm{cc}}(\theta, \mathrm{P}(\mathrm{j}, \mathrm{k}, \mathrm{l}))=\sum_{\mathrm{i}=1}^{\mathrm{s}} \mathrm{J}^{\mathrm{i}}{ }_{\mathrm{cc}}\left(\theta, \theta^{i}(\mathrm{j}, \mathrm{k}, \mathrm{l})\right)
$$




$$
\begin{aligned}
\sum_{\mathrm{i}=1}^{\mathrm{s}}\left[-\mathrm{d}_{\text {att }} \exp \left[-\mathrm{w}_{\text {att }} \sum_{\mathrm{m}=1}^{\mathrm{p}}\left(\theta_{\mathrm{m}}-\theta_{\mathrm{m}}{ }^{\mathrm{i}}\right)^{2}\right]\right] \\
+\sum_{\mathrm{i}=1}^{\mathrm{s}}\left[-\mathrm{h}_{\text {rep }} \exp \left[-\mathrm{w}_{\text {rep }} \sum_{\mathrm{m}=1}^{\mathrm{p}}\left(\theta_{\mathrm{m}}-\theta_{\mathrm{m}}{ }^{\mathrm{i}}\right)^{2}\right]\right]
\end{aligned}
$$

where, $\mathrm{d}_{\mathrm{att}}$ and $\mathrm{w}_{\mathrm{att}}$ are the depth and width of attractant respectively, $\mathrm{h}_{\text {rep }}$ and $\mathrm{w}_{\text {rep }}$ are the height and width of repellent respectively.

\section{Reproduction:}

In reproduction the health of each particle is computed with its fitness value (17). The least healthy particles can be identified by sorting the fitness value in ascending/ descending order. During reproduction, the least healthy particles, which mean the solution with worst fitness value (Maximum fitness value in minimization problems), are eventually neglected. The other healthier particles are split into two, which are then started exploring the search place from the same location. This maintains the population size as constant.

$$
\mathrm{j}_{\text {health }}^{\mathrm{i}}=\sum_{\mathrm{j}=1}^{\mathrm{N}_{\mathrm{c}}+1} \mathrm{~J}(\mathrm{i}, \mathrm{j}, \mathrm{k}, \mathrm{l})
$$

\section{Elimination- Dispersal:}

The elimination- dispersal operation takes place after a certain number of reproduction processes. The probability of elimination- dispersal $\mathrm{P}_{\mathrm{ed}}$ is already assigned at the stage of initialization. In optimization techniques the solution may be stuck around the initial or local optima positions. Hence, it is required to diversify the particles. In elimination- dispersal event, a particle is chosen according to a present probability $\mathrm{P}_{\text {ed }}$ and then dispersed/ moved to another position within the environment. This may disturb the optimization process but prevents the local minima trapping. The repetition of all these algorithmic steps will be carried on, until an optimal result is reached.

\subsection{Bacterial Foraging Particle Swarm Optimization Algorithm (BFPSO)}

The reproduction and elimination -dispersal steps in BFOA approach prevents the solution being trapped in local optima and makes the algorithm to produce global optimal solutions. However, during chemotaxis process, the performance of BFOA algorithm depends on random search directions which may delay the convergence of solution. In PSO algorithm, the ability of exchanging social information with personal best and global best solutions (8) seems to be more beneficial compared to BFOA. Nevertheless, in PSO algorithm the solutions may trap in past optimal or local minima depends on the speeds of particles. Hence, the hybrid BFPSO algorithm is designed in this paper, to combine the merits and to overcome the drawbacks of both PSO and BFOA [20]. The procedural steps of BFPSO algorithm is as follows:

Step 1: In addition to the BFOA, the following PSO parameters are also initialized for BFPSO.

Inertia weight $(\mathrm{w})=0.9$; Acceleration coefficients (c1 and $\mathrm{c} 2)=0.12$ and $1.2, \mathrm{r}_{1}, \mathrm{r}_{2}$ are two $\mathrm{n} \times \mathrm{n}$ diagonal matrices in which the entries in the main diagonal are random numbers uniformly distributed over an interval $(0,1)$

Step 2: The initial movement of randomly generated particles can be computed by Chemotaxis action of BFOA approach.

Step 3: For each particle i, at each chemotactic movement $\mathrm{j}$, compute the best fitness value as local best with the index of $\mathrm{J}_{\text {local }}(18)$ and the corresponding positions with a set of control parameters $\left(\mathrm{K}_{\mathrm{p}}, \mathrm{K}_{\mathrm{i}}, \mathrm{K}_{\mathrm{d}}\right)$ are predicted as local best positions $\mathrm{P}_{\text {local }}(19)$.

$$
\begin{gathered}
\left.J_{\text {local }}(j)=\mathrm{J}(\mathrm{i}, \mathrm{j}+1, \mathrm{k}, \mathrm{l})\right) \\
\mathrm{P}_{\text {local }}(\mathrm{j})=\mathrm{P}(\mathrm{i}, \mathrm{j}+1, \mathrm{k}, \mathrm{l})
\end{gathered}
$$

Step 4: At the end of each chemotactic movement, best fitness among $\mathrm{J}_{\text {local }}$ is evaluated and stored as $\mathrm{J}_{\text {global }}$ and the corresponding position of the particle is stored as $\mathrm{P}_{\text {global }}$.

Step 5: During the next iteration, the position of each particle will be changed (20) with the velocity equation (8) designed using PSO algorithm [20].

$$
\phi(j+1)=v(j+1)
$$

Step 6: Substitute (20) in (12) and repeat the algorithmic steps 2-6 over the specified number of chemotactic movements.

Step 7: Extend the algorithm with the significant reproduction operation and elimination- dispersal event as discussed in the BFOA algorithm.

\section{Results and Discussions}

In this section, the output transient performances of the LFC test system for Step Load Perturbation (SLP) if 1\% in area 1 is examined with BFPSO tuned PID controller employing conventional $\left(\mathrm{J}_{1}\right.$ and $\left.\mathrm{J}_{2}\right)$ and proposed $\left(\mathrm{J}_{3}\right)$ objective functions.

\section{Case 1: Transient performance analysis with conventional objective functions}

In this case, the control parameters of PID controller are optimized by employing conventional objective functions such as $\operatorname{ISE}\left(\mathrm{J}_{1}\right)$ and $\operatorname{ITSE}\left(\mathrm{J}_{2}\right)$ respectively $(2,3)$. A comparison study is done between the proposed BFPSO algorithm and the alternate approaches suggested in this research paper such as PSO, BFOA and also to the earlier documented results of CBPSO [17] algorithm. The Fig. 2(a), Fig. 2(b) and Fig. 2(c) shows the $\Delta \mathrm{F}_{1}, \Delta \mathrm{F}_{2}$ and $\Delta \mathrm{P}_{\text {tie }}$ 


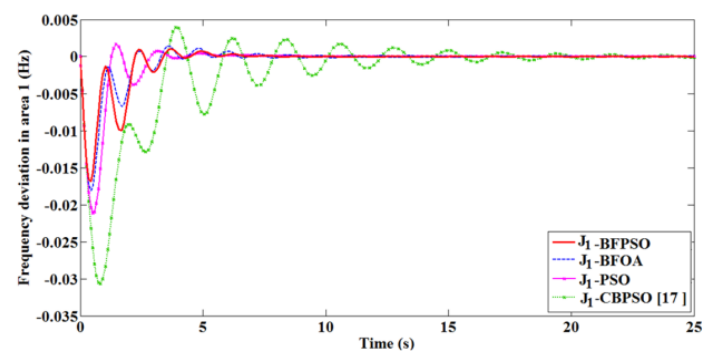

(a) $\Delta F_{1}$ response for SLP of $1 \%$ in area 1

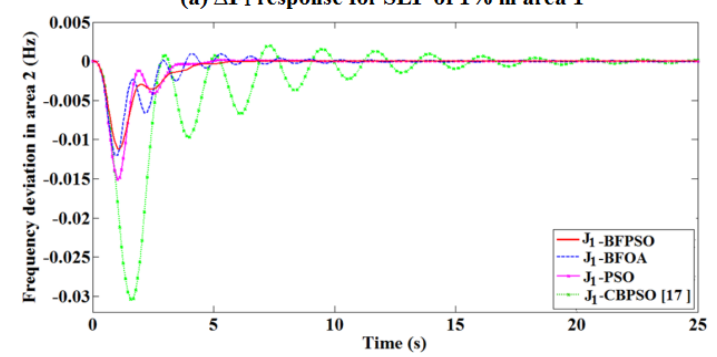

(b) $\Delta F_{2}$ response for SLP of $1 \%$ in area 1

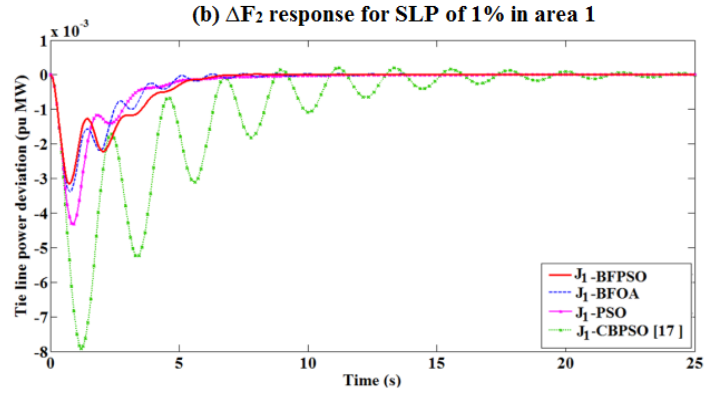

(c) $\triangle P_{\text {tie }}$ response for SLP of $1 \%$ in area 1

Fig. 2. Comparative output responses of two area LFC test system with ISE $\left(\mathrm{J}_{1}\right)$ objective function

Table 1. Transient performance analysis of LFC with ISE $\left(\mathrm{J}_{1}\right)$ objective functions

\begin{tabular}{|c|c|c|c|c|}
\hline $\begin{array}{c}\text { Output } \\
\text { Measurement }\end{array}$ & $\begin{array}{c}\text { BFPSO } \\
\left(\mathrm{J}_{1}\right) \\
\end{array}$ & $\begin{array}{c}\text { BFOA } \\
\left(J_{1}\right) \\
\end{array}$ & $\begin{array}{c}\mathrm{PSO} \\
\left(\mathrm{J}_{1}\right)\end{array}$ & $\begin{array}{c}\text { CBPSO }\left(\mathrm{J}_{1}\right) \\
{[17]}\end{array}$ \\
\hline $\mathrm{K}_{\mathrm{p} 1}$ & 0.6220 & 0.5596 & 0.4131 & -0.2514 \\
\hline $\mathrm{K}_{\mathrm{i} 1}$ & 0.9056 & 0.9910 & 0.8930 & 0.2491 \\
\hline $\mathrm{K}_{\mathrm{d} 1}$ & 0.7458 & 0.5964 & 0.3136 & 0 \\
\hline $\mathrm{K}_{\mathrm{p} 2}$ & 0.1472 & 0.3552 & 0.2653 & -0.2514 \\
\hline $\mathrm{K}_{\mathrm{i} 2}$ & 0.7164 & 0.5968 & 0.3377 & 0.2491 \\
\hline $\mathrm{K}_{\mathrm{d} 2}$ & 0.2351 & 0.8324 & 0.8506 & 0 \\
\hline \multicolumn{5}{|c|}{ Frequency deviation in area-1 $\left(\Delta \mathrm{F}_{1}\right)$} \\
\hline $\mathrm{E}_{\mathrm{ss}}\left(\mathrm{x} \quad 10^{-5} \mathrm{~Hz}\right)$ & 5.5 & 1.3 & 5.8 & 48 \\
\hline $\mathrm{T}_{\mathrm{s}}(\mathrm{s})$ & 9.7324 & 9.8368 & 6.9557 & 20.45 \\
\hline $\mathrm{P}_{\mathrm{m}}(\mathrm{Hz})$ & 0.0168 & 0.0180 & 0.0211 & 0.0307 \\
\hline $\mathrm{T}_{\mathrm{r}}(\mathrm{s})$ & 0.0035 & 0.0011 & 0.0023 & 0.0064 \\
\hline $\mathrm{T}_{\mathrm{p}}(\mathrm{s})$ & 0.4289 & 0.4439 & 0.5690 & 0.8140 \\
\hline \multicolumn{5}{|c|}{ Frequency deviation in area- $2\left(\Delta \mathrm{F}_{2}\right)$} \\
\hline $\mathrm{E}_{\mathrm{ss}}\left(\mathrm{x} 10^{-5} \mathrm{~Hz}\right)$ & 0.25 & 4.7 & 3.5 & 27 \\
\hline $\mathrm{T}_{\mathrm{s}}(\mathrm{s})$ & 7.0795 & 9.9268 & 7.0193 & 20.47 \\
\hline $\mathrm{P}_{\mathrm{m}}(\mathrm{Hz})$ & 0.0113 & 0.0122 & 0.0150 & 0.0305 \\
\hline $\mathrm{T}_{\mathrm{r}}(\mathrm{s})$ & 0.0088 & 0.0065 & 0.0309 & 0.1077 \\
\hline $\mathrm{T}_{\mathrm{p}}(\mathrm{s})$ & 1.0726 & 0.9548 & 1.1004 & 1.6110 \\
\hline \multicolumn{5}{|c|}{ Tie line power deviation $\left(\Delta \mathrm{P}_{\text {tie }}\right)$} \\
\hline $\mathrm{E}_{\mathrm{ss}}\left(\mathrm{x} 10^{-5} \mathrm{~Hz}\right)$ & 0.21 & 2.5 & 2.6 & 110 \\
\hline $\mathrm{T}_{\mathrm{s}}(\mathrm{s})$ & 9.3550 & 9.7440 & 8.3350 & 29.45 \\
\hline $\mathrm{P}_{\mathrm{m}}(\mathrm{Hz})$ & 0.0031 & 0.0034 & 0.0043 & 0.0079 \\
\hline $\mathrm{T}_{\mathrm{r}}(\mathrm{s})$ & 0.0141 & 2.4355 & 0.0237 & 0.1984 \\
\hline $\mathrm{T}_{\mathrm{p}}(\mathrm{s})$ & 0.7684 & 0.7552 & 0.8672 & 1.2110 \\
\hline
\end{tabular}

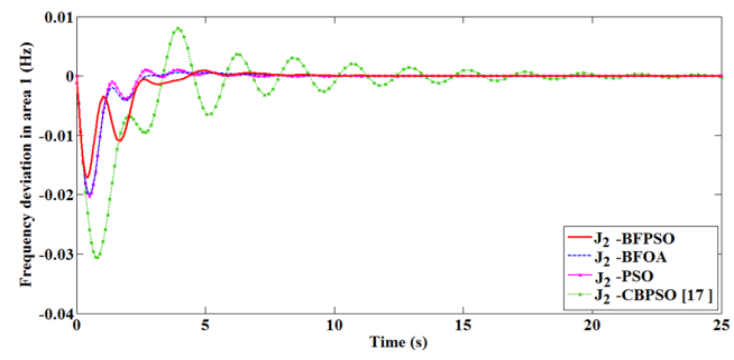

(a) $\Delta F_{1}$ response for SLP of $1 \%$ in area 1

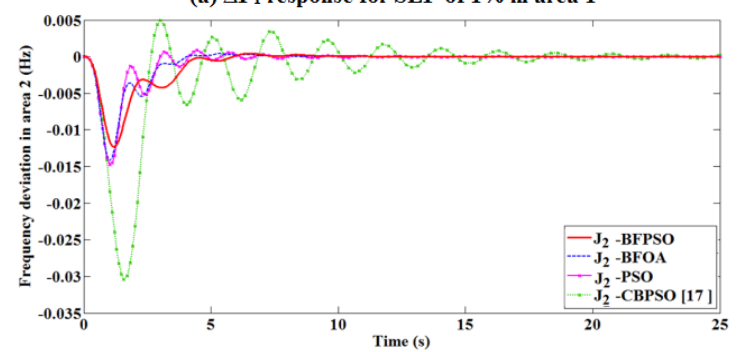

(b) $\triangle F_{2}$ response for $\mathrm{SLP}$ of $1 \%$ in area 1

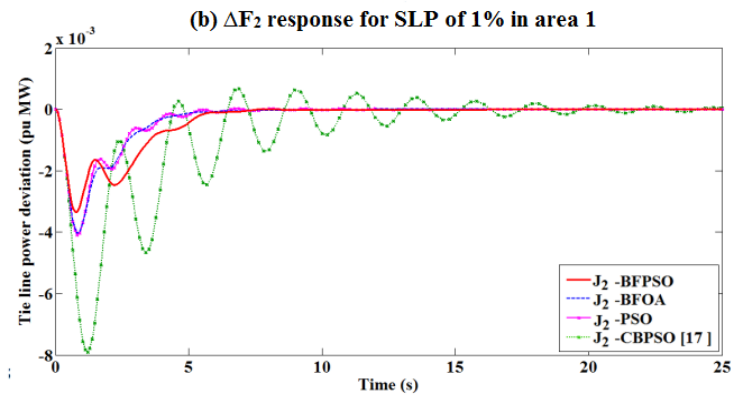

(c) $\triangle P_{\text {tie }}$ response for SLP of $1 \%$ in area 1

Fig. 3. Comparative output responses of two area LFC test system with ITSE $\left(\mathrm{J}_{2}\right)$ objective function

Table 2. Transient performance analysis of LFC with ITSE $\left(\mathrm{J}_{2}\right)$ objective functions

\begin{tabular}{|c|c|c|c|c|}
\hline $\begin{array}{c}\text { Output } \\
\text { Measurement }\end{array}$ & $\begin{array}{c}\text { BFPSO } \\
\left(\mathrm{J}_{2}\right)\end{array}$ & $\begin{array}{c}\text { BFOA } \\
\left(\mathrm{J}_{2}\right)\end{array}$ & $\begin{array}{c}\text { PSO } \\
\left(\mathrm{J}_{2}\right)\end{array}$ & $\begin{array}{l}\text { CBPSO } \\
\left(\mathrm{J}_{2}\right)[17] \\
\end{array}$ \\
\hline $\mathrm{K}_{\mathrm{p} 1}$ & 0.3706 & 0.3059 & 0.3412 & -0.2647 \\
\hline $\mathrm{K}_{\mathrm{i} 1}$ & 0.7436 & 0.8771 & 0.9213 & 0.3317 \\
\hline $\mathrm{K}_{\mathrm{d} 1}$ & 0.7256 & 0.4152 & 0.3976 & 0 \\
\hline $\mathrm{K}_{\mathrm{p} 2}$ & 0.2541 & 0.2813 & 0.5756 & -0.2647 \\
\hline $\mathrm{K}_{\mathrm{i} 2}$ & 0.2772 & 0.3955 & 0.6906 & 0.3317 \\
\hline $\mathrm{K}_{\mathrm{d} 2}$ & 0.0565 & 0.8824 & 0.7416 & 0 \\
\hline \multicolumn{5}{|c|}{ Frequency deviation in area-1 $\left(\Delta \mathrm{F}_{1}\right)$} \\
\hline $\mathrm{E}_{\mathrm{ss}}\left(\mathrm{x} 10^{-5} \mathrm{~Hz}\right)$ & 5.5 & 3.5 & 2.2 & 100 \\
\hline $\mathrm{T}_{\mathrm{s}}(\mathrm{s})$ & 9.3167 & 7.5824 & 7.9454 & 21.66 \\
\hline $\mathrm{P}_{\mathrm{m}}(\mathrm{Hz})$ & 0.0171 & 0.0200 & 0.0202 & 0.0307 \\
\hline $\mathrm{T}_{\mathrm{r}}(\mathrm{s})$ & 0.0182 & 0.0166 & 0.0003 & 0.0140 \\
\hline $\mathrm{T}_{\mathrm{p}}(\mathrm{s})$ & 0.4332 & 0.4648 & 0.4838 & 0.8172 \\
\hline \multicolumn{5}{|c|}{ Frequency deviation in area- $2\left(\Delta \mathrm{F}_{2}\right)$} \\
\hline $\mathrm{E}_{\mathrm{ss}}\left(\mathrm{x} 10^{-5} \mathrm{~Hz}\right)$ & 6.7 & 2.3 & 1.6 & 77 \\
\hline $\mathrm{T}_{\mathrm{s}}(\mathrm{s})$ & 9.1660 & 7.9599 & 9.2080 & 21.67 \\
\hline $\mathrm{P}_{\mathrm{m}}(\mathrm{Hz})$ & 0.0123 & 0.0141 & 0.0147 & 0.0304 \\
\hline $\mathrm{T}_{\mathrm{r}}(\mathrm{s})$ & 0.0429 & 0.0109 & 0.0017 & 0.0232 \\
\hline $\mathrm{T}_{\mathrm{p}}(\mathrm{s})$ & 1.1712 & 1.0533 & 1.1045 & 1.6103 \\
\hline \multicolumn{5}{|c|}{ Tie line power deviation $\left(\Delta \mathrm{P}_{\text {tie }}\right)$} \\
\hline $\mathrm{E}_{\mathrm{ss}}\left(\mathrm{x} 10^{-5} \mathrm{~Hz}\right)$ & 1.0 & 1.8 & 0.72 & 78 \\
\hline $\mathrm{T}_{\mathrm{s}}(\mathrm{s})$ & 8.0419 & 8.3107 & 7.5618 & 30.80 \\
\hline $\mathrm{P}_{\mathrm{m}}(\mathrm{Hz})$ & 0.0034 & 0.0040 & 0.0041 & 0.0079 \\
\hline $\mathrm{T}_{\mathrm{r}}(\mathrm{s})$ & 0.0191 & 0.0214 & 0.0182 & 0.1654 \\
\hline$T_{p}(s)$ & 0.7782 & 0.8487 & 0.8684 & 1.2103 \\
\hline
\end{tabular}


responses with $\mathrm{J}_{1}$ objective function and Fig. 3(a), Fig. 3(b) and Fig. 3(c) shows $\Delta \mathrm{F}_{1}, \Delta \mathrm{F}_{2}$ and $\Delta \mathrm{P}_{\text {tie }}$ responses with $\mathrm{J}_{2}$ objective function.

For detailed description, the essential transient parameters such as steady state error $\left(\mathrm{E}_{\mathrm{ss}}\right)$, maximum peak $\left(\mathrm{P}_{\mathrm{m}}\right)$, settling time $\left(T_{s}\right)$, rise time $\left(T_{r}\right)$ and peak time $\left(T_{p}\right)$ are measured from the output responses of LFC test system for PSO, BFOA and BFPSO approaches and the results are tabulated. The transient parameters measured from Fig. 2(a)-2(c) employing $J_{1}$ objective function are listed in Table 1 and measured from Fig. 3(a)-3(c) are listed in Table 2 respectively.

The Table 1 clearly reveals that, the main transient parameters such as maximum peak and steady state error of both frequency deviation and tie line power deviation are much reduced by the proposed BFPSO approach. And also the rise time and peak time in $\Delta \mathrm{F}_{1}, \Delta \mathrm{F}_{2}$ and $\Delta \mathrm{P}_{\text {tie }}$ responses are also much reduced by the proposed BFPSO approach.

In the same way, the Table 2 evidently proves that, the maximum peak and peak time of frequency deviation responses are much reduced by the proposed BFPSO compared to PSO and BFOA approaches and all the transient parameters measured in $\Delta \mathrm{P}_{\text {tie }}$ responses are significantly reduced by the proposed BFPSO algorithm compared to PSO, BFOA and CBPSO [17] approaches. Hence, it can be concluded that the transient performances employing both conventional objective functions are much improved with the proposed BFPSO approach compared to all other optimization techniques.

Table 3. Transient performance analysis of LFC with proposed $\left(\mathrm{J}_{3}\right)$ objective functions

\begin{tabular}{|c|c|c|c|c|}
\hline $\begin{array}{c}\text { Output } \\
\text { Measurement }\end{array}$ & $\begin{array}{c}\text { BFPSO } \\
\text { Proposed } \\
\mathrm{J}_{3} \\
\end{array}$ & $\begin{array}{c}\text { BFOA } \\
\text { Proposed } \\
\mathrm{J}_{3} \\
\end{array}$ & $\begin{array}{c}\text { PSO } \\
\text { Proposed } \\
\mathrm{J}_{3} \\
\end{array}$ & $\begin{array}{c}\text { CBPSO } \\
\text { Obj.fn1 } \\
\text { Proposed [17] }\end{array}$ \\
\hline $\mathrm{K}_{\mathrm{p} 1}$ & 0.7357 & 0.7536 & 0.4028 & -0.5762 \\
\hline $\mathrm{K}_{\mathrm{i} 1}$ & 0.7473 & 0.9920 & 0.8334 & 0.1962 \\
\hline $\mathrm{K}_{\mathrm{d} 1}$ & 0.8288 & 0.6807 & 0.7946 & 0 \\
\hline $\mathrm{K}_{\mathrm{p} 2}$ & 0.2864 & 0.6130 & 0.2702 & -0.5762 \\
\hline $\mathrm{K}_{\mathrm{i} 2}$ & 0.0127 & 0.8086 & 0.4495 & 0.1962 \\
\hline $\mathrm{K}_{\mathrm{d} 2}$ & 0.1717 & 0.1493 & 0.3690 & 0 \\
\hline \multicolumn{5}{|c|}{ Frequency deviation in area-1 $\left(\Delta \mathrm{F}_{1}\right)$} \\
\hline $\mathrm{E}_{\mathrm{ss}}\left(\mathrm{x} \quad 10^{-5} \mathrm{~Hz}\right)$ & 0.48 & 2.7 & 4.3 & 42 \\
\hline $\mathrm{T}_{\mathrm{s}}(\mathrm{s})$ & 8.5070 & 9.7577 & 8.7761 & 9.65 \\
\hline $\mathrm{P}_{\mathrm{m}}(\mathrm{Hz})$ & 0.0162 & 0.0172 & 0.0166 & 0.0339 \\
\hline $\mathrm{T}_{\mathrm{r}}(\mathrm{s})$ & 0.0001 & 0.0004 & 0.0047 & 0.0055 \\
\hline$T_{p}(s)$ & 0.4165 & 0.4397 & 0.4217 & 1.0523 \\
\hline \multicolumn{5}{|c|}{ Frequency deviation in area-2 $\left(\Delta \mathrm{F}_{2}\right)$} \\
\hline $\mathrm{E}_{\mathrm{ss}}\left(\mathrm{x} \quad 10^{-5} \mathrm{~Hz}\right)$ & 0.015 & 3.2 & 1.1 & 59 \\
\hline $\mathrm{T}_{\mathrm{s}}(\mathrm{s})$ & 8.7564 & 8.9093 & 9.4878 & 10.98 \\
\hline $\mathrm{P}_{\mathrm{m}}(\mathrm{Hz})$ & 0.0104 & 0.0121 & 0.0112 & 0.0372 \\
\hline $\mathrm{T}_{\mathrm{r}}(\mathrm{s})$ & 0.0030 & 0.0020 & 0.0106 & 0.1445 \\
\hline$T_{p}(s)$ & 1.0708 & 1.0924 & 1.0787 & 1.8814 \\
\hline \multicolumn{5}{|c|}{ Tie line power deviation $\left(\Delta \mathrm{P}_{\text {tie }}\right)$} \\
\hline $\mathrm{E}_{\mathrm{ss}}\left(\mathrm{x} \quad 10^{-5} \mathrm{~Hz}\right)$ & 1.0 & 0.42 & 0.22 & 26 \\
\hline $\mathrm{T}_{\mathrm{s}}(\mathrm{s})$ & 9.3004 & 8.8269 & 9.0667 & 13.16 \\
\hline $\mathrm{P}_{\mathrm{m}}(\mathrm{Hz})$ & 0.0030 & 0.0032 & 0.0031 & 0.0093 \\
\hline $\mathrm{T}_{\mathrm{r}}(\mathrm{s})$ & 0.0192 & 0.0125 & 0.0066 & 0.0982 \\
\hline$T_{p}(s)$ & 0.7263 & 0.7878 & 0.7099 & 1.4814 \\
\hline
\end{tabular}

\section{Case 2: Transient performance analysis with proposed objective function $\left(\mathrm{J}_{3}\right)$}

The effectiveness of the proposed BFPSO approach is already exemplified with $J_{1}$ and $J_{2}$ objective function in earlier cases. For further enhancement of control performances, the transient analysis of the test system is examined in this case with a proposed novel objective function $\left(\mathrm{J}_{3}\right)$, which is designed with fundamental time domain transient measuring parameters (4).

The simulated performances of test system $\Delta \mathrm{F}_{1}, \Delta \mathrm{F}_{2}$ and $\Delta \mathrm{P}_{\text {tie }}$ corresponding to these optimal control parameters are illustrated in Fig. 4(a), Fig. 4(b) and Fig. 4(c). The transient measurements of these figures are tabulated in Table 3.

To demonstrate the effectiveness of the proposed objective function $\mathrm{J}_{3}$, the designed PSO, BFOA and BFPSO approaches employing $\mathrm{J}_{3}$ objective function are compared with an objective function 1 of CBPSO approach [17], which has been proven as a prominent one in that reference.

The Table 3 distinctly proves that, the output frequency responses of the system in both areas $\left(\Delta \mathrm{F}_{1}, \Delta \mathrm{F}_{2}\right)$ by the proposed BFPSO tuned PID controller employing $\mathrm{J}_{3}$ objective function are enormously improved with minimal values of settling time, peak time, rise time and peak time.

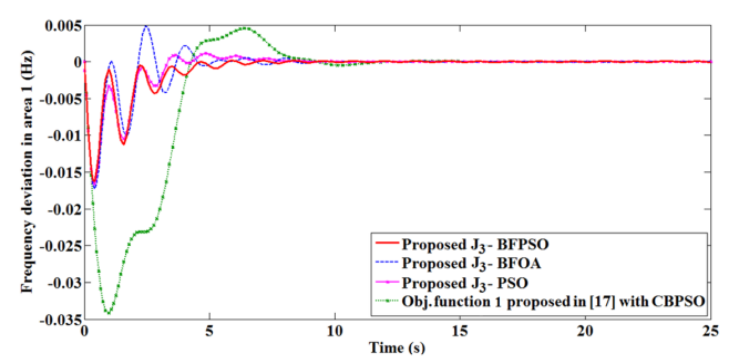

(a) $\Delta F_{1}$ response for $\operatorname{SLP}$ of $1 \%$ in area 1

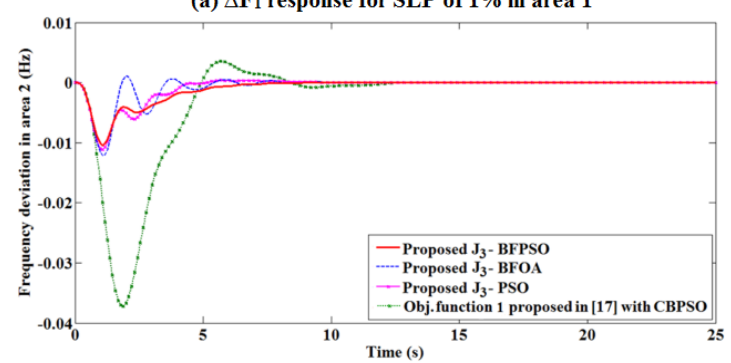

(b) $\Delta \mathbf{F}_{2}$ response for SLP of $1 \%$ in area 1

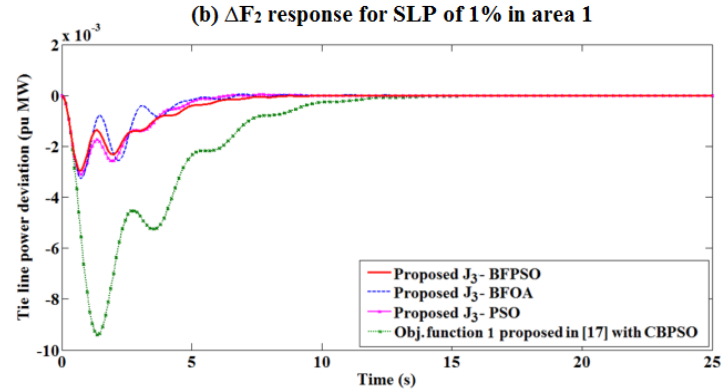

(c) $\Delta P_{\text {tie }}$ response for SLP of $1 \%$ in area 1

Fig. 4. Comparative output responses of two area LFC test system with Proposed $\left(\mathrm{J}_{3}\right)$ objective function 
In addition, the comparison of Table 1, Table 2 and Table 3 in all the three cases evidently approves that, remarkable control performances can be obtained with a BFPSO tuned PID controller with the $\mathrm{J}_{3}$ objective function.

\subsection{Convergence Analysis}

All the optimization problems are targeted to have better convergence characteristics with a minimum convergence time. The evolutionary tendency of optimization algorithms is investigated with the convergence of output, and is measured through the fitness value of system response over consecutive iterations. Moreover, the convergence can also be visualized through the positional values of particles over the iterations.

The Fig. 5 describes the comparison of fitness values evaluated through PSO, BFOA and BFPSO with $\mathrm{J}_{1}, \mathrm{~J}_{2}$ and $\mathrm{J}_{3}$ objective functions respectively over consecutive iterations. The Fig. 6 describes the positional values of the PID controller gain parameters $\left(\mathrm{K}_{\mathrm{p} 1}, \mathrm{~K}_{\mathrm{i} 1}, \mathrm{~K}_{\mathrm{d} 1}, \mathrm{~K}_{\mathrm{p} 2}, \mathrm{~K}_{\mathrm{i} 2}\right.$ and $\mathrm{K}_{\mathrm{d} 2}$ ) over consecutive iterations employing $\mathrm{J}_{1}, \mathrm{~J}_{2}$ and $\mathrm{J}_{3}$ objective functions respectively. It is apparent from Fig. 5(a), Fig. 5(b) and Fig. 5(c) that earlier convergence can be obtained with the proposed BFPSO approach compared to PSO and BFOA in all $\mathrm{J}_{1}, \mathrm{~J}_{2}$ and $\mathrm{J}_{3}$ objective functions.

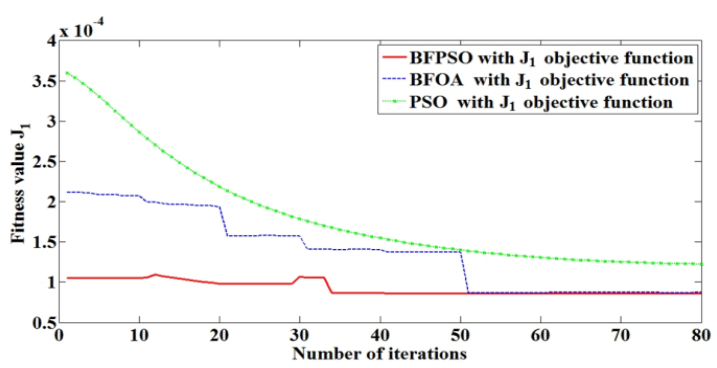

(a) Convergence analysis with fitness value $\mathbf{J}_{1}$

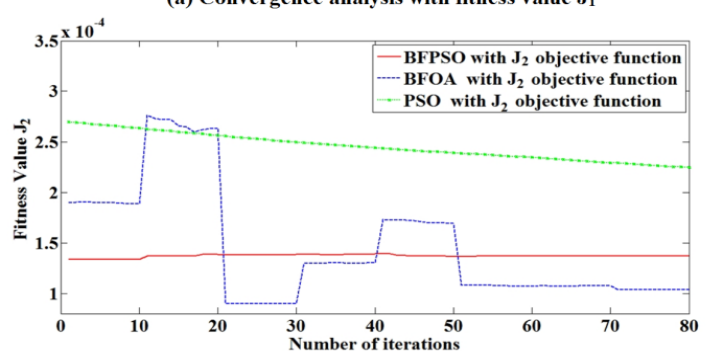

(b) Convergence analysis with fitness value $\mathbf{J}_{2}$

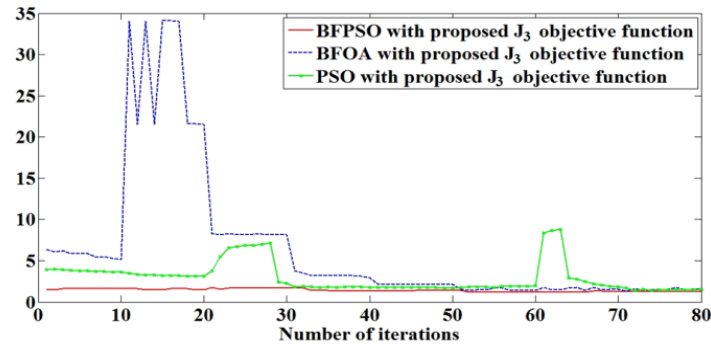

(c) Convergence analysis with fitness value $\mathrm{J}_{3}$

Fig. 5. Convergence analysis with fitness values
Also, from these figures it is confirmed that the final fitness value of the proposed BFPSO approach with $\mathrm{J}_{3}$ objective function is minimum compared to other optimization approaches. Likewise, from the positional values of the control parameters $\left(\mathrm{K}_{\mathrm{p} 1}, \mathrm{~K}_{\mathrm{i} 1}, \mathrm{~K}_{\mathrm{d} 1}, \mathrm{~K}_{\mathrm{p} 2}, \mathrm{~K}_{\mathrm{i} 2}\right.$ and $\left.\mathrm{K}_{\mathrm{d} 2}\right)$ shown in Fig. 6(a), Fig. 6(b) and Fig. 6(c), it is well understood that the PSO and BFOA algorithms possess erratic positional values with all $\mathrm{J}_{1}, \mathrm{~J}_{2}$ and $\mathrm{J}_{3}$ objective functions and the BFPSO algorithm has consistent convergence characteristics with all objective functions. Especially, the proposed BFPSO with proposed $\mathrm{J}_{3}$ objective function exhibits preferable better convergence characteristics compared to other optimization methods and other objective functions.

\subsection{Robustness analysis of LFC system under load variations}

The superiority of proposed BFPSO algorithm with proposed $\mathrm{J}_{3}$ objective function has been proved as an effective tuning methodology in the sections 4.1 and 4.2 discussed so far. Hence, in this section, the robustness of

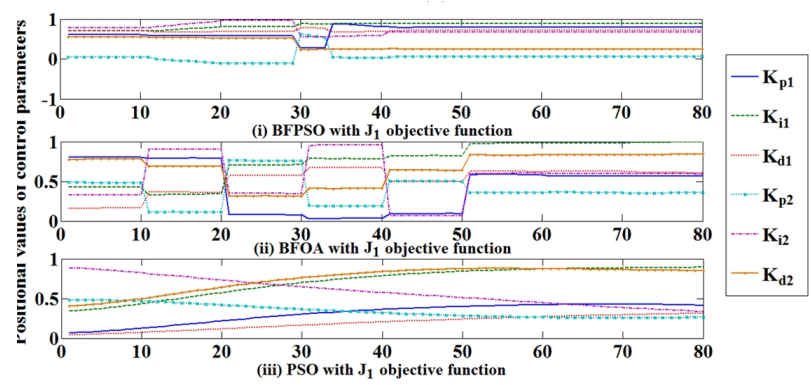

(a) Comparison of positional values with $\mathrm{J}_{1}$ objective function

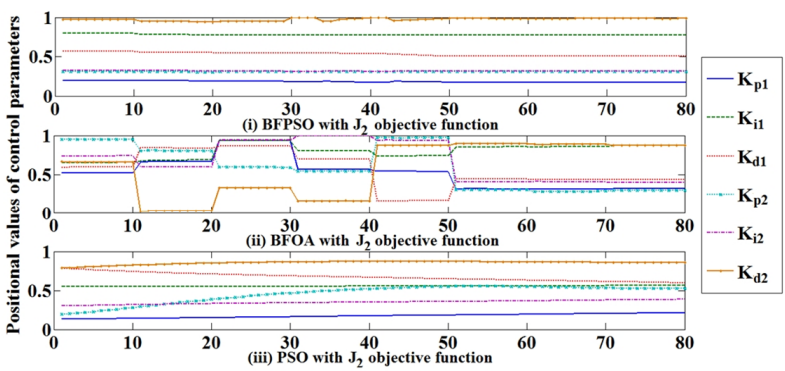

(b) Comparison of positional values with $\mathrm{J}_{2}$ objective function

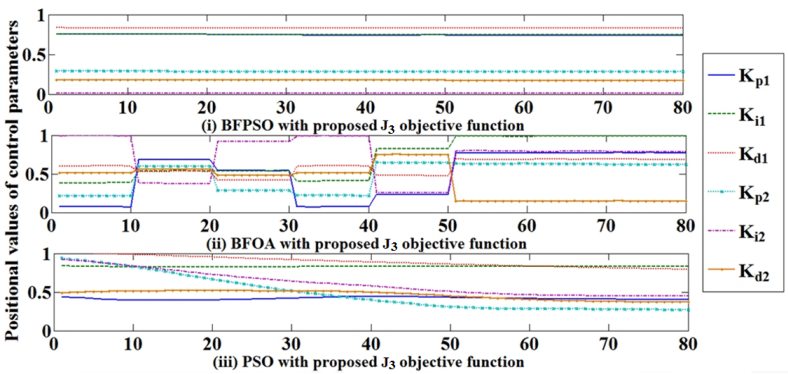

(c) Comparison of positional values with $\mathrm{J}_{3} \mathrm{objective} \mathrm{function}$

Fig. 6. Convergence analysis with positional values of controller gain parameters 
Table 4. BFPSO optimized PID controller parameters under load variations

\begin{tabular}{c|c|c|c|c|c|c}
\hline \multirow{2}{*}{$\begin{array}{c}\text { Load } \\
\text { Variations }\end{array}$} & \multicolumn{5}{c}{ Tuned control parameters of PID controller } \\
\cline { 2 - 7 } & \multicolumn{5}{|c|}{ Area 1} & \multicolumn{3}{c}{ Area-2 } \\
\cline { 2 - 7 } & $\mathrm{K}_{\mathrm{p} 1}$ & $\mathrm{~K}_{\mathrm{i} 1}$ & $\mathrm{~K}_{\mathrm{d} 1}$ & $\mathrm{~K}_{\mathrm{p} 2}$ & $\mathrm{~K}_{\mathrm{i} 2}$ & $\mathrm{~K}_{\mathrm{d} 2}$ \\
\hline \multicolumn{6}{c}{ BFPSO algorithm with proposed objective function $\mathrm{J}_{3}$} \\
\hline$-50 \%$ & 0.3979 & 0.8900 & 0.1939 & 0.5609 & 0.7768 & 0.7728 \\
\hline$-25 \%$ & 0.0719 & 0.7138 & 0.5420 & 0.1295 & 0.0107 & 0.8037 \\
\hline$+25 \%$ & 0.2607 & 0.8417 & 0.8235 & 0.2342 & 0.2042 & 0.5452 \\
\hline$+50 \%$ & 0.2109 & 0.6574 & 0.4294 & 0.1195 & 0.4731 & 0.7373 \\
\hline CBPSO algorithm with proposed objective function 1 in reference [17] \\
\hline$-50 \%$ & -0.5478 & 0.2162 & 0 & -0.5478 & 0.2162 & 0 \\
\hline$-25 \%$ & -0.4428 & 0.2000 & 0 & -0.4428 & 0.2000 & 0 \\
\hline$+25 \%$ & -0.4000 & 0.2464 & 0 & -0.4000 & 0.2464 & 0 \\
\hline$+50 \%$ & -0.5389 & 0.2098 & 0 & -0.5389 & 0.2098 & 0 \\
\hline
\end{tabular}

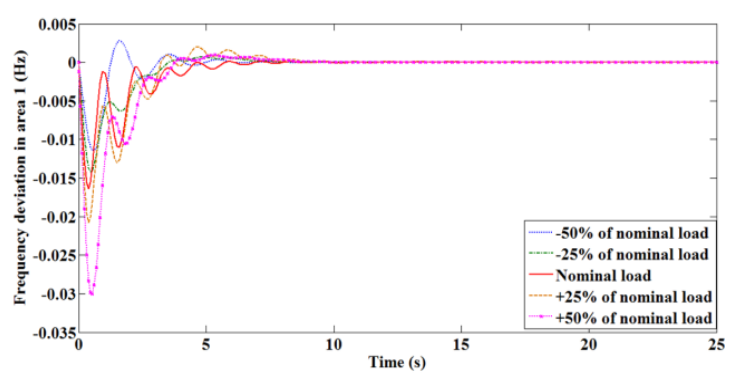

(a) $\Delta \mathbf{F}_{1}$ response under load variations

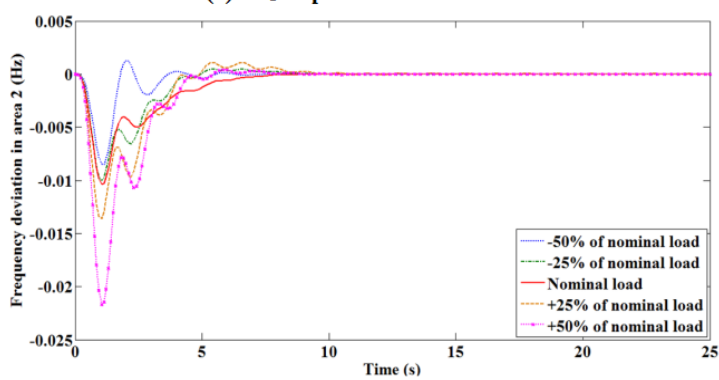

(b) $\Delta \mathbf{F}_{2}$ response under load variations

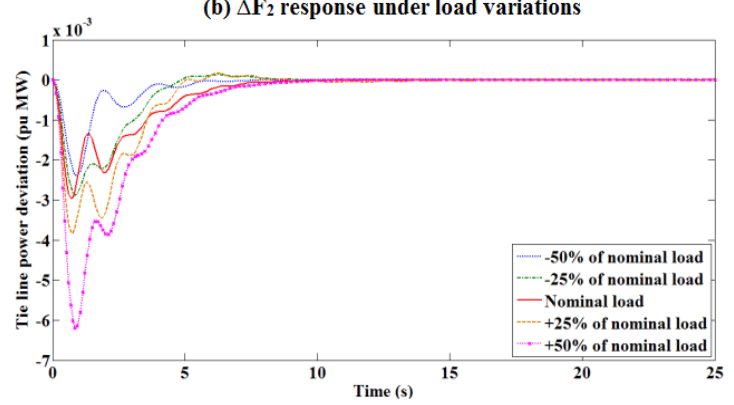

(c) $\Delta \mathbf{P}_{\text {tie }}$ response under load variations

Fig. 7. Robustness analysis of the LFC system with variable load perturbations in area-1

the system under a wide range of load variation is examined with the proposed BFPSO with $\mathrm{J}_{3}$ objective function.

Generally, the frequency deviation and tie line power deviation responses in LFC system changes according to load fluctuations. To analyse these changes, the operating load conditions are changed by $\pm 50 \%$ from their nominal values and related control parameters are optimized with
Table 5. Output transient measuring parameters of LFC system under load variations

\begin{tabular}{c|c|c|c|c|c}
\hline \multirow{2}{*}{$\begin{array}{c}\text { Load } \\
\text { Change }\end{array}$} & \multicolumn{5}{|c}{ Output transient measurements } \\
\cline { 2 - 6 } & Outputs & $\begin{array}{c}\text { Settling } \\
\text { Time(s) }\end{array}$ & $\begin{array}{c}\text { Maximum } \\
\text { Peak(V) }\end{array}$ & $\begin{array}{c}\text { Rise } \\
\text { time(s) }\end{array}$ & $\begin{array}{c}\text { Peak } \\
\text { time(s) }\end{array}$ \\
\hline \multicolumn{5}{c}{ BFPSO algorithm with proposed objective function $\mathrm{J}_{3}$} \\
\hline \multirow{4}{*}{$-50 \%$} & $\Delta \mathrm{F}_{1}$ & 7.7337 & 0.0115 & 0.0001 & 0.5805 \\
\cline { 2 - 6 } & $\Delta \mathrm{F}_{2}$ & 7.2380 & 0.0086 & 0.0002 & 1.0433 \\
\cline { 2 - 6 } & $\Delta \mathrm{P}_{\text {tie }}$ & 7.4793 & 0.0024 & 0.0005 & 0.9221 \\
\hline \multirow{4}{*}{$-25 \%$} & $\Delta \mathrm{F}_{1}$ & 7.8094 & 0.0142 & 0.0001 & 0.4967 \\
\cline { 2 - 6 } & $\Delta \mathrm{F}_{2}$ & 9.2840 & 0.0100 & 0.0002 & 1.0019 \\
\cline { 2 - 6 } & $\Delta \mathrm{P}_{\text {tie }}$ & 9.0468 & 0.0029 & 0.0153 & 0.8801 \\
\hline \multirow{4}{*}{$+25 \%$} & $\Delta \mathrm{F}_{1}$ & 9.7349 & 0.0207 & $3.68 \mathrm{X} 10^{-5}$ & 0.4037 \\
\cline { 2 - 6 } & $\Delta \mathrm{F}_{2}$ & 9.4474 & 0.0136 & 0.0103 & 1.0488 \\
\cline { 2 - 6 } & $\Delta \mathrm{P}_{\text {tie }}$ & 9.0376 & 0.0038 & 0.0220 & 0.7738 \\
\hline \multirow{4}{*}{$+50 \%$} & $\Delta \mathrm{F}_{1}$ & 8.3783 & 0.0301 & 0.0043 & 0.5214 \\
\cline { 2 - 6 } & $\Delta \mathrm{F}_{2}$ & 8.4912 & 0.0218 & 0.0007 & 1.0882 \\
\cline { 2 - 6 } & $\Delta \mathrm{P}_{\text {tie }}$ & 8.9694 & 0.0062 & 0.0152 & 0.8648 \\
\hline
\end{tabular}

CBPSO algorithm with proposed objective function 1 in reference

\begin{tabular}{c|c|c|c|c|c}
\multicolumn{7}{|c|}{$[17]$} \\
\hline \multirow{3}{*}{$-50 \%$} & $\Delta \mathrm{F}_{1}$ & 9.4996 & 0.01580 & 0.0056 & 0.9982 \\
\cline { 2 - 6 } & $\Delta \mathrm{F}_{2}$ & 9.7576 & 0.01817 & 0.1673 & 1.8735 \\
\cline { 2 - 6 } & $\Delta \mathrm{P}_{\text {tie }}$ & 9.5522 & 0.00472 & 0.0471 & 1.2735 \\
\hline \multirow{3}{*}{$-25 \%$} & $\Delta \mathrm{F}_{1}$ & 13.3350 & 0.02293 & 0.0003 & 0.9958 \\
\cline { 2 - 6 } & $\Delta \mathrm{F}_{2}$ & 13.6201 & 0.02570 & 0.0094 & 1.6511 \\
\cline { 2 - 6 } & $\Delta \mathrm{P}_{\text {tie }}$ & 17.8662 & 0.00673 & 0.0092 & 1.3508 \\
\hline \multirow{3}{*}{$+25 \%$} & $\Delta \mathrm{F}_{1}$ & 14.5808 & 0.03764 & 0.0004 & 0.7935 \\
\cline { 2 - 6 } & $\Delta \mathrm{F}_{2}$ & 14.5705 & 0.04171 & 0.0202 & 1.5658 \\
\cline { 2 - 6 } & $\Delta \mathrm{P}_{\text {tie }}$ & 15.5580 & 0.01098 & 0.0120 & 1.3028 \\
\hline \multirow{3}{*}{$+50 \%$} & $\Delta \mathrm{F}_{1}$ & 10.5185 & 0.04726 & $8.32 \mathrm{X} 10^{-8}$ & 1.0269 \\
\cline { 2 - 6 } & $\Delta \mathrm{F}_{2}$ & 11.5159 & 0.05429 & 0.0116 & 1.6667 \\
\cline { 2 - 6 } & $\Delta \mathrm{P}_{\text {tie }}$ & 13.7992 & 0.01411 & 0.0010 & 1.3652 \\
\hline
\end{tabular}

the proposed approach as listed in Table 4. The output performances of LFC system simulated with these tuned parameters are presented in Fig. 7(a)-(c). For detailed description, the transient measurements corresponding to these figures are also portrayed in Table 5. It is welldefined from these tables that, for the entire range of load variations, improved output responses of the system with reduced frequency and tie line power deviations, settling time, rise time and peak time can be obtained with the proposed BFPSO with $\mathrm{J}_{3}$ objective function when compared with CBPSO [17]. The maximum deviations in the system output responses are also much reduced by the proposed control strategy which ensures the robustness and stable control performances against the load variations.

\subsection{Testing the reliability of the proposed BFPSO tuned PID controller in IEEE 30 bus power system}

In this section, the reliability of the proposed hybrid BFPSO tuned PID controller in LFC control loop is examined with the IEEE 30 bus system. The IEEE 30 bus system is shown in Fig. 8. The IEEE 30 bus system contains six generators and the configurations of each generator are given in earlier research article [21]. In this research article, a comparative LFC study is conducted 


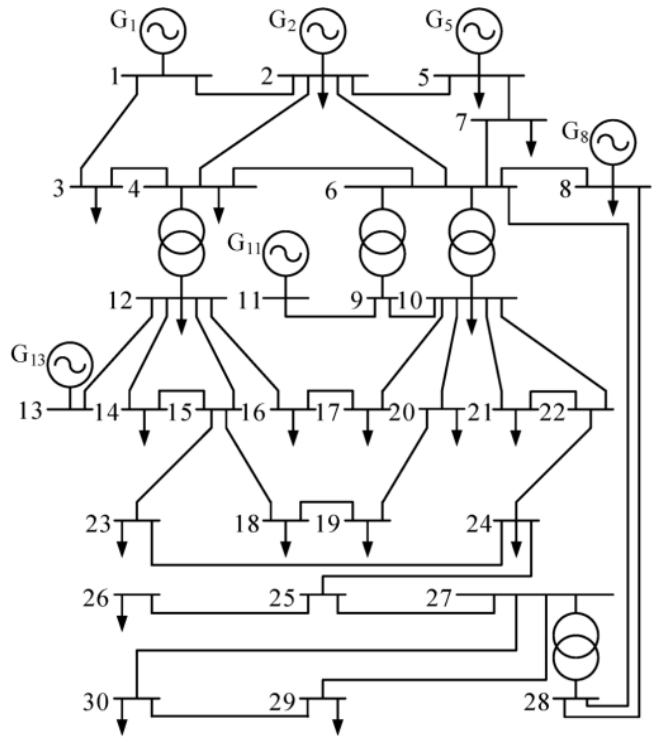

Fig. 8. IEEE 30 bus system

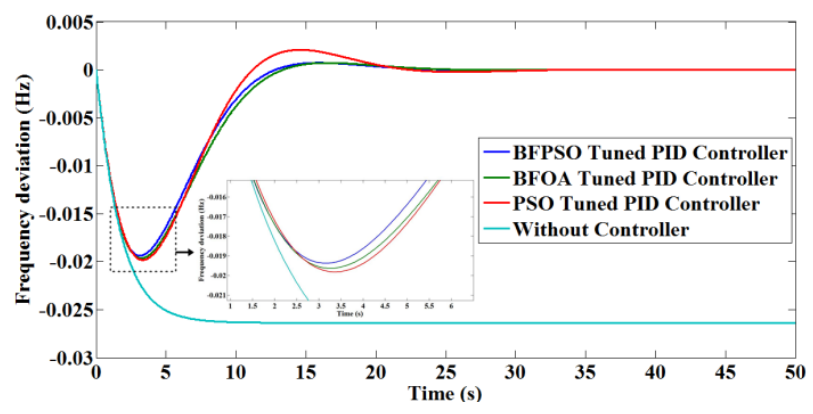

Fig. 9. Output response of generator 1 (IEEE 30 bus system)

Table 6. Transient performance analysis in generator 1 of IEEE 30 bus system

\begin{tabular}{|c|c|c|c|}
\hline $\begin{array}{c}\text { Output } \\
\text { Measurement }\end{array}$ & BFPSO & BFOA & PSO \\
\hline \multicolumn{4}{|c|}{ Optimized PID controller gain values } \\
\hline $\mathrm{K}_{\mathrm{p}}$ & 0.9802 & 0.9144 & 0.5927 \\
\hline $\mathrm{K}_{\mathrm{i}}$ & 0.8148 & 0.7729 & 0.8905 \\
\hline $\mathrm{K}_{\mathrm{d}}$ & 0.0466 & 0.1454 & 0.5826 \\
\hline \multicolumn{4}{|c|}{ Output frequency response measurements } \\
\hline $\mathrm{E}_{\mathrm{ss}}(\mathrm{Hz}) \times 10^{-8}$ & 5.1921 & 19.828 & 21.365 \\
\hline $\mathrm{T}_{\mathrm{s}}(\mathrm{s})$ & 23.1373 & 24.0541 & 30.0275 \\
\hline $\mathrm{P}_{\mathrm{m}}(\mathrm{Hz})$ & 0.0194 & 0.0196 & 0.0198 \\
\hline $\mathrm{T}_{\mathrm{r}}(\mathrm{s}) \times 10^{-5}$ & 7.1509 & 28.882 & 12.089 \\
\hline $\mathrm{T}_{\mathrm{p}}(\mathrm{s})$ & 3.1529 & 3.2512 & 3.3556 \\
\hline
\end{tabular}

between the proposed hybrid BFPSO approach and alternate algorithms named BFOA and PSO in generator 1 of the IEEE 30 bus system

The configurations of generator 1 in IEEE 30 bus system are given as follows: Hydraulic time constant $\mathrm{T}_{\mathrm{Hi}}=0.06 \mathrm{~s}$, Turbine time constant $\mathrm{T}_{\mathrm{Ti}}=0.44 \mathrm{~s}$, governor speed regulation $\mathrm{R}_{\mathrm{i}}=2.7273 \mathrm{~Hz} / \mathrm{pu}$, Frequency bias constant $\mathrm{B}_{\mathrm{i}}=0.3827$ $\mathrm{pu} / \mathrm{Hz}$, Inertia constant $2 \mathrm{H}=12.102 \mathrm{~s}$ [21]. Initially, the load flow analysis is carried out in IEEE 30 bus system with Newton-Raphson method. The power generation in generator 1 is given as $161.4 \mathrm{MW}$ [21]. The total real power demand to the generator 1 which is connected bus 1 , 2 and 3 was evaluated from the load flow results as 260.928 MW. Hence the increase in power generation can be evaluated as $99.528 \mathrm{MW}$ and this increase in power generation is given as the step change in input to the LFC loop.

The PID gain parameters are then optimized with the hybrid BFPSO, BFOA and PSO algorithms corresponding to the step change in input and their valued are listed in Table 6. The output transient performance of the LFC system in generator 1 of the IEEE 30 bus system corresponding to this tuned gain parameters of various intelligent algorithms (BFPSO, BFOA and PSO) and a non controller system are depicted in Fig. 9. The output fundamental transient parameters are measured from this figure and tabulated as shown in Table 6 .

It is very clear from both Fig. 9 and Table 6 that, the frequency error in generator 1 of IEEE 30 bus system is tuned to be zero with the proposed BFPSO controller with less steady state error, peak overshoot, settling time, rise time and peak time compared to BFOA, PSO and a system without any controller. Hence, the reliability of the proposed approach is again verified in the IEEE 30 bus system.

\section{Conclusion}

In this research paper, tuning of PID controller in a two area interconnected LFC system with GDB nonlinearity is formulated as an optimization problem and detailed analysis has been made to select a suitable algorithm to search for optimal control parameters are discussed. Hybrid BFPSO algorithm has been suggested for optimal tuning of PID controller in the LFC test system.

Minimization of error in frequency responses and also the tie line power response is the main objective of LFC system. A novel objective function, which includes the essential time domain specifications with a proper weighting factor, is also proposed in this paper to enhance the dynamic performance of the system and the supremacy is proved over conventional objective functions.

Three significant analysis named, transient analysis, convergence analysis and robustness analysis are carried out on the test system with the proposed BFPSO approach employing proposed objective function. The results of transient analysis ensured that better dynamic performances can be obtained with the proposed approach over designed PSO, BFOA approaches and recently documented results of CBPSO. The results of convergence analysis confirmed that the BFPSO with proposed objective function converge very fast and has consistent convergence characteristics over successive iterations. Furthermore, the robustness 
analysis again assured that, the LFC system optimized by BFPSO tuned PID controller is affected very less for any sort of uncertainty. The reliability of the proposed approach is also verified in one of the generators in IEEE 30 bus system.

Hence, it is confirmed from all the analysis performed in this research work that, the BFPSO algorithm with proposed objective function is designated as a suitable one for effective tuning of PID controller in LFC system and it can control the system optimally and robustly.

\section{References}

[1] Hassan Bevrani, Pourya Ranjbar Daneshmand, Poya Babahajyani, Yasunori Mitani and Takashi Hiyama, "Intelligent LFC Concerning High Penetration of Wind Power: Synthesis and Real-time Application," IEEE Transactions on Sustainable Energy, vol. 5 (2), pp. 655-662, 2013.

[2] Hadi Saadat, Power system analysis: New York, Mc Graw-Hill, 1999.

[3] Katsuhiko Ogata, System dynamics: India, Pearson Education, 2008.

[4] Qing-Guo Wang, Zhen Ye, Wen-Jian Cai, ChangChieh Hang, "PID Control for Multi Variable Processes," Lecture notes in control and Information Science, Springer, pp. 1-5, 2008.

[5] Ahmad M. Hamza, Mohamed S. Saad. Hassan M. Rashad, Ahmed Bahgat, "Design of LFC and AVR for Single Area Power System with PID Controller Tuning By BFO and Ziegler Methods," International Journal of Computer Science and Telecommunications, vol. 4 (5), pp. 12-17, 2013.

[6] Hamed Shabani, Behrooz Vahidi, Majid Ebrahimpour, "A Robust PID Controller Based on Imperialist Competitive Algorithm for Load-frequency Control of Power Systems," ISA Transactions, vol. 52, pp. 88-95, 2013.

[7] Seyed Abbas Taher, Masoud Hajiakbari Fini, Saber Falahati Aliabadi, "Fractional Order PID Controller Design for LFC in Electric Power Systems using Imperialist Competitive Algorithm," Ain Shams Engineering Journal, vol. 5, pp. 121-135, 2014.

[8] K. Naidu, H. Mokhlis, A. H. A. Bakar, "Multi Objective Optimization using Weighted Sum Artificial Bee Colony Algorithm for Load Frequency Control," International Journal of Electrical power and Energy systems, vol. 55, pp. 657-667, 2014.

[9] Puja Dash, Lalit Chandra Saikia, Nidul Sinha, "Comparison of performances of several Cuckoo Search Algorithm Based 2DOF Controllers in AGC of Multiarea Thermal System," International Journal of Electrical power and Energy systems, vol. 55, pp. 429-436, 2014.
[10] Ioan Cristian Trelea, "The Particle Swarm Optimization Algorithm: Convergence Analysis and Parameter Selection," Information Processing Letters, vol. 85, pp. 317-325 2003.

[11] K. M. Passino, "Bacterial foraging optimization," International Journal of Swarm Intelligence Research, vol. 1 (1), pp. 1-16, 2010.

[12] E. S. Ali, S. M. Abd-Elazim, "BFOA Based Design of PID Controller for Two Area Load Frequency Control with Nonlinearities," International Journal of Electrical power and Energy systems, vol. 51, pp. 2242312013.

[13] Anbarasi Soundarapandian, Muralidharan Srinivasan, "Application of Bacterial Foraging Optimization Algorithm for Improving Control and Stability," Technics Technologies Education Management, vol. 9 (2), pp. 479-486, 2014.

[14] S. M. Abd-Elazim, E. S. Ali, "A Hybrid Particle Swarm Optimization and Bacterial Foraging for Optimal Power System Stabilizers Design," International Journal of Electrical power and Energy systems, vol. 46, pp. 334-341, 2013.

[15] Sidhartha Panda, Banaja Mohanty, P. K. Hotaa, "Hybrid BFOA-PSO Algorithm for Automatic Generation Control of Linear and Nonlinear Interconnected Power Systems," Applied Soft Computing, vol. 13, pp. 4718-4730, 2013.

[16] Dong Hwa Kim, "Hybrid GA-BF Based Intelligent PID Controller Tuning for AVR System," Applied Soft Computing, vol. 11, pp. 11-22, 2011.

[17] Haluk Gozde, Cengiz Taplamacioglu M, “Automatic Generation Control Application with Craziness Based Particle Swarm Optimization in a Thermal Power System," International Journal of Electrical power and Energy systems, vol. 33, pp. 8-16, 2011.

[18] Rabindra Kumar Sahu, Sidhartha Panda, Umesh Kumar Rout, "DE Optimized Parallel 2-DOF PID Controller for Load Frequency Control of Power System with Governor Dead-band Nonlinearity", International Journal of Electrical power and Energy systems, vol. 49, pp. 19-33, 2013.

[19] Swagatam Das, Arijit Biswas, Sambatra Dasgupta, Ajith Abraham, "Bacterial Foraging Optimization Algorithm: Theoretical Foundations, Analysis, and Applications," Foundations of Computational Intelligence, vol. 3, pp. 23-55, 2009.

[20] W. M Korani, "Bacterial Foraging Oriented by Particle Swarm Optimization Strategy for PID Tuning," IEEE International Symposium on Computational Intelligence in Robotics and Automation (CIRA), Daejeon, pp. 445-450, 2009.

[21] K. N Vijayakumar, Power system network splitting and load frequency control optimization using $A B C$ based algorithms: Thesis report, University of Malaya, 2015. 


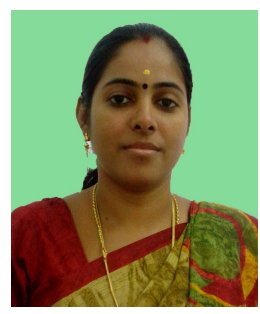

S. Anbarasi She received her B.E degree in electrical and electronics engineering from Madurai Kamaraj University in 2003 and her M.E degree in power system engineering from Anna University in 2005. Currently she is pursuing a Ph.D degree in Anna University .Her research interests are power system operation and control, soft computing techniques and intelligent and robust control applications in power systems.

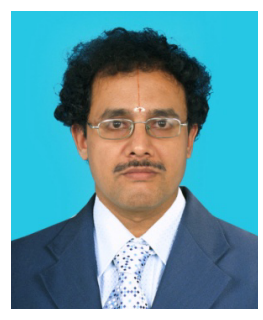

S. Muralidharan $\mathrm{He}$ is working as a Professor in Mepco Schlenk Engineering College, Sivakasi, India. He completed his Bachelors degree at Madurai Kamaraj University in 1994 and obtained his Masters degree from Birla Institute of Science and Technology, Pilani, India in 1997. He completed his Doctoral degree from SASTRA University, Tanjore in 2009. His research interests include power systems, renewable energy integration and soft computing techniques applications in power systems. He has published several research papers in various International Journals including IEEE-Power Electronics. He is a member of various professional bodies. 